\title{
Comparison of hypoxia transcriptome in vitro with in vivo gene expression in human bladder cancer
}

\author{
JJ Ord', EH Streeter', ISD Roberts², D Cranston' and AL Harris*,3 \\ 'Department of Urology, Churchill Hospital, Oxford, UK; ${ }^{2}$ Department of Cellular Pathology, John Radcliffe Hospital, Oxford, UK; ${ }^{3}$ Institute of Molecular \\ Medicine, Cancer Research UK Laboratory, John Radcliffe Hospital, Oxford, UK
}

Hypoxia-inducible genes have been linked to the aggressive phenotype of cancer. However, nearly all work on hypoxia-regulated genes has been conducted in vitro on cell lines. We investigated the hypoxia transcriptome in primary human bladder cancer using cDNA microarrays to compare genes induced by hypoxia in vitro in bladder cancer cell line EJ28 with genes upregulated in 39 bladder tumour specimens (27 superficial and 12 invasive). We correlated array mRNA fold changes with carbonic anhydrase 9 (CA IX) staining of tumours as a surrogate marker of hypoxia. Of 6000 genes, 32 were hypoxia inducible in vitro more than two-fold, five of which were novel, including lactate transporter SLCI6A3 and RNAse 4. Eight of 32 hypoxia-inducible genes in vitro were also upregulated on the vivo array. Vascular endothelial growth factor mRNA was upregulated two-fold by hypoxia and 2- | 8-fold in 3| out of 39 tumours. Glucose transporter I was also upregulated on both arrays mRNA, and fold changes on the in vivo array significantly correlated with CA IX staining of tumours $(P=0.008)$. However, insulin-like growth factor binding protein 3 mRNA was the most strongly differentially expressed gene in both arrays and this confirmed its upregulation in urine of bladder cancer patients $(n=157, P<0.01)$. This study defines genes suitable for an in vivo hypoxia 'profile', shows the heterogeneity of the hypoxia response and describes new hypoxia-regulated genes.

British Journal of Cancer (2005) 93, 346-354. doi:I0.I038/sj.bjc.6602666 www.bjcancer.com

Published online 19 July 2005

(c) 2005 Cancer Research UK

Keywords: microarray; hypoxia; carcinoma; bladder; HIF

Invasive bladder cancer has a mortality of approximately $50 \%$ and new approaches to treatment include inhibiting angiogenesis or targeting hypoxia cells. We and others have previously shown the importance of angiogenic factors, such as vascular endothelial growth factor (VEGF) measured in the urine or in the tumour, in mediating bladder tumour angiogenesis (Chow et al, 1999; Crew et al, 1999; Crew et al, 2000). We showed striking luminal induction of VEGF in superficial bladder cancer (Turner et al, 2002). Vascular endothelial growth factor is a key angiogenic factor and microvessel density as a measure of angiogenesis has been shown to be highly associated with poor outcome in invasive bladder cancer (Bochner et al, 1995). Vascular endothelial growth factor is well recognised to be induced by hypoxia via hypoxia inducible factor (HIF) and this suggests that genes induced by hypoxia may be related to the aggressive phenotype. Indeed many proteins upregulated by hypoxia play a role in invasion such as urokinase plasminogen activator receptor, matrix metalloproteinase 2 and cathepsin D. Direct clinical measurements of tumour hypoxia with Eppendorf electrodes have shown it to be independently related to prognosis, being associated with aggressive local growth, metastasis and treatment failure whether from radiotherapy or surgery, although these have not been done in

*Correspondence: Professor AL Harris; E-mail: aharris.lab@cancer.org.uk Received 20 December 2004; revised 3 May 2005; accepted 18 May 2005; published online 19 July 2005 bladder cancer (Brizel et al, 1996; Hockel et al, 1996; Nordsmark and Overgaard, 2000).

Apart from intratumoural hypoxia, genetic alterations also upregulate HIF; loss of tumour suppressor genes such as PTEN and activation of $\mathrm{H}$-ras induce $\mathrm{HIF}$, and these alterations are common in bladder cancer.

Carbonic anhydrase IX (CA IX) is an extracellular enzyme attached to the cell membrane that may generate the acidic $\mathrm{pH}$ of tumours. We previously demonstrated the induction of CA IX by hypoxia, its regulation by HIF and its correlation with tissue hypoxia measured by oxygen electrodes in cervical cancer (Airley et al, 2001). We also demonstrated that bladder cancers show widespread staining for CA IX on the luminal surface and perinecrotic areas (Turner et al, 2002). Clinical studies also correlated the expression of CA IX with staining of bladder tumours by pimonidazole (Wykoff et al, 2000). A recent study also shows that bladder cancers expressing HIF have a poor prognosis independent of stage and grade (Theodoropoulos et al, 2004). Thus, hypoxia has a substantial role in bladder cancer biology.

We hypothesised that other hypoxia-regulated genes might be significantly expressed in bladder cancer and relevant to its biology. Since most analysis of genes induced by hypoxia has been on cell lines in vitro, we analysed gene expression in primary tumours $v s$ comparator cell lines in normoxia. We considered that genes upregulated in our tumour array would include those induced by hypoxia since our comparator cell lines were in normoxia. 
We defined a hypoxia-upregulated profile of genes in an invasive bladder cancer cell line (EJ28) and compared the expression of those genes with those upregulated in 39 primary bladder tumours. This contrasts with other expression arrays published for bladder cancer where a panel of four bladder cancer cell lines (Sanchez-Carbayo et al, 2003) or four normal bladder tissue samples (Dyrskjot et al, 2003) were used as reference. Using the in vitro induced genes, we were able to define for each tumour an in vivo hypoxia profile. We then stained 33 available tumours from the expression study for CA IX as a surrogate marker of hypoxia and compared the in vivo hypoxia gene profile with tumour CA IX staining and necrosis. We also defined a hypoxiaupregulated profile of genes from a single culture of normal urothelial cells cultured from a strip of fresh human ureter. As insulin-like growth factor binding protein 3 (IGFBP-3) was one of the most induced and expressed genes in cancer and normal urothelia in vitro and on the in vivo array, in a separate set of 157 urine samples from bladder cancer patients and controls we analysed protein levels of IGFBP-3.

\section{MATERIALS AND METHODS}

\section{Cell culture}

Bladder cell lines were cultured in Dulbecco's modified Eagle's medium (DMEM) with HEPES (EJ28, 253J 2T10) or RPMI $1 \%$ (RT112) and supplemented with $1 \mathrm{~mm}$ glutamine (GibcoBRL, UK), $0.002 \mathrm{mg} \mathrm{ml}^{-1}$ puromycin and $10 \%$ fetal bovine serum (FBS) (Globepharm, UK), in a humidified atmosphere of $5 \% \mathrm{CO}_{2}$ at $37^{\circ} \mathrm{C}$. Human umbilical vein endothelial cells (HUVE cells) were maintained in MCDB 131 (Gibco, Paisley, Scotland, UK). Human umbilical vein endothelial cells were purchased from Clonetics BioWhittaker (Wokingham, Berkshire, UK) and were cultured in MCDB 131 medium (Invitrogen, Paisley, Scotland, UK) containing $20 \%$ fetal calf serum (Sigma-Aldrich), $100 \mathrm{U} \mathrm{ml}^{-1}$ penicillin, $100 \mu \mathrm{g} \mathrm{ml}^{-1}$ streptomycin, $2 \mathrm{mM}$ glutamine, $5 \mathrm{IU} \mathrm{ml}^{-1}$ heparin and $50 \mu \mathrm{g} \mathrm{ml}^{-1}$ endothelial cell growth supplement (Sigma, Dorset, UK). Human umbilical vein endothelial cells were grown on plates coated with $0.2 \%$ gelatine, and were used up to the 8 th passage. Cells were exposed to hypoxia by incubation in a humidified atmosphere of $0.1 \% \mathrm{O}_{2}, 5 \% \mathrm{CO}_{2}$ and the remainder $\mathrm{N}_{2}$ in a NAPCO 7301 incubator (Precision Scientific, USA).

\section{Normal urothelial culture}

Samples of ureter were collected with informed consent and approval from the Local Research Ethics Committee. A strip of ice-cooled fresh normal human ureter from a patient undergoing nephrectomy for renal cell cancer was placed in stripper medium (0.1\% EDTA, $10 \mathrm{~mm}$ HEPES, Trasylol $500000 \mathrm{IU}$ in $500 \mathrm{ml}$ Hank's Balanced Salt Solution minus calcium and magnesium) for $6 \mathrm{~h}$ at $4{ }^{\circ} \mathrm{C}$. The urothelial lining was scraped off, digested with collagenase for $30 \mathrm{~min}$ and plated on collagen-coated plates (Becton Dickinson, NJ, USA) and cultured as previously described (Cordon-Cardo et al, 1984; Dubeau and Jones, 1987; Schaafsma et al, 1989). Cytospins were performed and cells stained for URO5 antibody, Cytokeratin 7 and Cytokeratin 20 confirming urothelium as the cell of origin.

\section{RNA extraction and storage}

RNA was extracted using $7 \mathrm{ml}$ Trireagent (Sigma, UK) per $75 \mathrm{~cm}^{2}$ dish. Concentrations of RNA and purity were assessed on a UV spectrometer. The integrity of the mRNA in this total RNA sample was checked by running the RNA on a $1 \%$ agarose gel. Tumour samples were collected with informed consent and approval from the Local Research Ethics Committee.

\section{Sanger microarrays, chips and analysis}

Hver 1.2.1 cDNA microarrays were obtained from the Microarray Consortium, Sanger Centre, Hinxton, Cambridge, UK. These arrays contain 9932 spotted samples of cDNA originating from the I.M.A.G.E. collections of the Human Genome mapping Project and Research Genetics, Hinxton, UK, representing approximately 6000 human genes in total. A GSI Lumionics Scan Array 400 array reader with Scanarray and Quantarray $\AA$ software was used to analyse the slides. The analysed data were imported into GeneSpring $\mathbb{R}$ software (Silicon Genetics, USA). Data were normalised internally by region on each chip (regional normalisation) to compensate for systematic variation over the surface of the array. The mathematical Lowess correction was applied to allow for nonlinear fluorescence characteristics of the dyes.

\section{Generation of cell line reference RNA}

To provide a controlled reference for each competitive hybridisation, a panel of 11 cell lines was harvested while in exponential growth in culture (SK23, NCI-H1385, NCI-H69, IM-9, MCF-7, OVCAR-3, MOLT-4, HEPG2, SW620, HT1376, W38). These cell lines were selected according to previously published work at Stanford (Perou et al, 2000) in order to reliably provide a constant level of expression over the vast majority of genes on the array.

Generation of fluorescently labelled single-stranded cDNA and competitive hybridisation of labelled single-stranded cDNA

Between 25 and $50 \mu$ g total RNA in $75 \%$ ethanol was mixed with $1 \mu \mathrm{l}$ of bacterial RNA cocktail (as internal control) and applied to the microarray slide. This slide was placed in a hybridisation chamber humidified with hybridisation buffer. Incubation occurred at $47^{\circ} \mathrm{C}$ for $12-24 \mathrm{~h}$. The slides were then placed in a slide rack and washed in darkness in three different solutions containing SSC and $0.1 \%$ SDS on a tilting table for $1 \mathrm{~h}$. Slides were dried by centrifugation.

\section{Microarray analysis of genes upregulated by hypoxia $(0.1 \%)$ in cell line EJ28}

We analysed gene expression in an aggressive bladder cancer cell line EJ28 under normoxia and 16 and $24 \mathrm{~h}$ hypoxia $(0.1 \%)$. There were four replicates at each time point grown in separate plates compared with normoxic cells from the same passage harvested at the same time.

\section{Microarray analysis of 39 bladder cancers compared with cancer cell line panel}

The labelled cDNA from 39 bladder cancers was hybridised to the chip with labelled cDNA from a panel of 11 cancer cell lines from different types of cancer.

\section{Real-time reverse transcription-polymerase chain reaction $(\mathrm{RT}-\mathrm{PCR})$}

We used a commercial probe and primer sets (Applied Biosystems, USA) for genes of interest. After RT of RNA (Invitrogen), cDNA was diluted down to $0.5 \mu \mathrm{g} \mu \mathrm{l}^{-1}$. The gene probe had an FAM reporter dye. We chose Beta-2-microglobulin (B2M) as a control gene as this is not known to be upregulated by hypoxia in the literature, and was not upregulated by hypoxia in the cell line on the array (data not shown). The relative Delta $\mathrm{Ct}$ technique of real-time analysis was used looking at changes in cycle threshold between three normoxic replicates and three hypoxic replicates. 
Two-tailed nonparametric $t$-tests $(P<0.05)$ were used to analyse the difference between replicates.

\section{Bladder tumour tissue microarray}

A tissue array was made from paraffin blocks of 33 available gene array cases. Whole sections of bladder cancer stained with haematoxylin and eosin were reviewed under light microscopy by a consultant histopathologist (IR) specialising in urological cancer and one researcher (JO). Scoring of whole slides for necrosis $\quad$ (negative $=$ none, positive $=$ either comedo or gross intratumoral necrosis) was done blinded to the array results. Tissue arrays are accepted forms of rapidly assessing antibodies on a panel of tumours. The cores are significantly representative of the whole block so long as at least two cores are used and regional differences in staining are taken into account when selecting cores (Camp et al, 2000; Nocito et al, 2001). Carbonic anhydrase IX staining is known to be expressed in bladder cancer and to occur more frequently around areas of necrosis (Wykoff et al, 2000). We therefore selected two $1 \mathrm{~mm}$ cores from representative areas of tumour and if any necrotic areas existed another two perinecrotic cores.

\section{Carbonic anhydrase IX staining and scoring of tissue array}

The tissue array was stained with the CA IX antibody M75 as described (Wykoff et al, 2000). Scoring was as described (Turner et al, 2002): a score of $0-3(0=$ no staining, $3=$ strong staining in $>50 \%$ of the core) was given based on intensity and area of membrane staining of tumour cells. Scores from more than one core were summed. Carbonic anhydrase IX positivity was defined as a score $>1.5$, which was the median score. Correlation of tumour CA IX staining scores with gene fold changes for all eight genes individually and summed was tested using linear regression. Goodness of fit was calculated as $r^{2}$ and $P<0.05$ cutoff taken for a significantly nonzero slope.

\section{Urine collection}

Urine was collected with informed consent fresh from patients with histologically confirmed bladder cancer, an average of 1 week before operation as described (Crew et al, 1999). There were 69 superficial cancers, 19 invasive, four carcinoma in situ, 34 patients who had previously had bladder cancer resected and were now clear, and 29 controls. Of 29 controls, 12 were $43-80$ years old who had full investigations for haematuria with no bladder cancer found; the remaining 17 were medical student volunteers aged $18-30$ years with no blood in the urine on dipstix. Urine levels of IGFBP3 were compared using a two-tailed $t$-test, nonparametric with significance cutoff $P<0.05$.

\section{RESULTS}

\section{Array results in bladder cancer cell line}

We minimised false positive genes by initially including those with raw absolute values of $>1000$. Of 6000 genes analysed, $32(0.53 \%)$ were upregulated by hypoxia in the cell line EJ28 more than two-fold in at least six of eight replicates (four at $16 \mathrm{~h}$ and four at $24 \mathrm{~h}$ ) (Table 1). Adrenomedullin (ADM), upregulated 17-fold, and IGFBP-3, upregulated 12-fold, were the most upregulated genes, with VEGF less at 2.5-fold. Adrenomedullin is known to have a range of effects on vasculature including vasodilatation and angiogenesis (Nikitenko et al, 2002). Insulin-like growth factor binding protein 3 is the major binding protein for insulin-like growth factors in the blood and also has IGF-independent apoptotic effects. Nearly all genes either increased or retained the upregulation found at $16 \mathrm{~h}$ and at $24 \mathrm{~h}$. These genes divided into functional groups typical of hypoxia-induced genes (Harris, 2002) (Table 1). Several genes not previously known to be upregulated by hypoxia included Ribonuclease 4 RNAse4 3.1-fold, monocarboxylate transporter family member 4 (SLC16A3 also called MCT4), Preferentially expressed antigen of melanoma PRAME 4.9-fold and Importin Beta 34.1 -fold. The protein kinase $\mathrm{C}$ substrate MARCKS also appeared upregulated 2.2 -fold at $16 \mathrm{~h}$.

\section{Validation of hypoxia-upregulated genes by RT - PCR in EJ28, bladder cancer cell lines and primary urothelial and endothelial cell culture}

Six genes were analysed: IGFBP-3, RNAse4, SLC16A3, MARCKS, using two controls B2M and Peroxiredoxin. Two novel genes not previously known to be upregulated by hypoxia in vitro were RNAse 4 and SLC16A3 (a lactate transporter chosen for its potential relevance to hypoxia). Both were confirmed to be upregulated in a panel of cell lines (Table 2). SLC16A3 RNA was also upregulated by hypoxia in HUVE cells but not in cultured normal urothelium. RNAse 4 like IGFBP-3 was upregulated by hypoxia in the cell lines and normal urothelial cells. The control gene B2M showed no significant change by comparison. Nor did a second control gene Peroxiredoxin selected from the tumour array by its lack of fold change (data not shown). MARCKS was upregulated by hypoxia 2.1-fold on the in vitro array. However, MARCKS upregulation in the cell line panel was not confirmed.

\section{Array results in primary bladder tumours}

Of 6000 genes on the tumour arrays, $70(1.2 \%)$ were upregulated more than two-fold in over 30 tumours. We compared the results for hypoxia-regulated genes from the cell line with the bladder tumour array (Figure 1). Of the 32 genes upregulated by hypoxia in vitro, eight genes were upregulated more than two-fold with raw signal intensity $>1000$ in more than five of the 39 tumours. Vascular endothelial growth factor, which is known to be expressed in bladder cancer, was upregulated 2.5 -fold by hypoxia and 2-18-fold in 31 out of 39 tumours making it the second most frequently upregulated hypoxia-inducible gene. The most highly and frequently upregulated gene in both arrays, however, was the mRNA IGFBP-3. This was upregulated up to 12 -fold by hypoxia in vitro and from 2 to 100 -fold in 33/39 tumours compared to the cell line panel. The other six genes with more than two-fold upregulation in more than five tumours arrayed were CCNG2 in 30 tumours, NDRG1 in 18 tumours, PFKFB3 in 17 tumours, RNAse4 in 10 tumours, Adrenomedullin (ADM) in eight tumours and Glucose transporter 1 (GLUT-1) in six tumours. The cumulative fold changes for all eight genes are plotted for each tumour (Figure 2). It can be seen that IGFBP-3 is more upregulated than the others in individual tumours.

Of 32 genes upregulated by hypoxia in vitro, 24 were downregulated on the in vivo array (definition of downregulated - more than 0.5 -fold lower in more than five tumour samples). The most downregulated gene in vivo was lactate dehydrogenase. Genes that were most induced in vitro were more likely to be upregulated in vivo; six of the 10 most hypoxia-induced genes on the in vitro array were upregulated in the in vivo array $v$ s only one of the remaining genes ( $P=0.02$ Fisher's exact test six out of $10 \mathrm{vs}$ one out of 13).

SLC16A3 was strongly regulated in tumour cell lines and HUVE cells in vitro and although signal was low in tumours it was upregulated more than two-fold in seven tumours. A paired $t$-test of the raw data showed significant upregulation (mean control signal 520, mean raw signal 690 , ratio $1.3, P=0.0003$ ). To see if this occurred in cell lines from other tumour types, two breast cancer cell lines were studied (T47D, MDA 468) and also showed induction (Table 2). 
Table I Mean fold changes of all 32 genes upregulated more than two-fold by hypoxia (0.1\%) at 16 and $24 \mathrm{~h}$ in cell line EJ28

\begin{tabular}{|c|c|c|c|c|}
\hline \multirow[b]{2}{*}{ No. } & \multicolumn{2}{|c|}{ Fold change at hypoxia } & \multirow[b]{2}{*}{ Gene } & \multirow[b]{2}{*}{ Functional group } \\
\hline & $16 \mathrm{~h}$ & $24 \mathrm{~h}$ & & \\
\hline \multicolumn{5}{|c|}{ Known to be hypoxia upregulated in other cell lines } \\
\hline I & 3.4 & 17 & Adrenomedullin (ADM)* & Angiogenesis \\
\hline 2 & 2.6 & 12.1 & Insulin-like growth factor binding protein 3 (IGFBP-3)* & Apoptosis \\
\hline 3 & 2.9 & 8.2 & n-myc downstream regulated protein I (NDRGI)* & Cell cycle \\
\hline 4 & 5.3 & 6.6 & NIP3 & Proapoptotic \\
\hline 5 & 2.7 & 4.7 & Induclble 6-phosphofructo-2-klnase (PFKFB3)* & Glucose metabolism \\
\hline 6 & 2.4 & 4.7 & Lysyl hydroxylase (PLOD2) & Tissue remodelling \\
\hline 7 & 2.2 & 4.4 & MAX interacting protein I & Transcription factor \\
\hline 8 & 3.1 & 4.2 & Glucose transporter I (GLUT I)* & Glucose metabolism \\
\hline 9 & 2.3 & 3.9 & I,4-Alpha glucan branching enzyme & Glucose metabolism \\
\hline 10 & 2.2 & 3.8 & Cyclin G2* & Cell cycle \\
\hline | | & 2.5 & 3.7 & Proline-4-hydroxylase (P4HAI) & Oxygen sensing \\
\hline 12 & 3.2 & 3.2 & Adenylate kinase 4 & Energy metabolism \\
\hline 13 & 2.9 & 3.1 & Aldolase C & Glucose metabolism \\
\hline 14 & 1.9 & 3 & Prolyl-4-hydroxylase alpha subunlt & Oxygen sensing \\
\hline 15 & 1.8 & 2.6 & Haem oxygenase I & Haem degradation \\
\hline 16 & 2.5 & 2.5 & EGL9 homologue I & Oxygen sensing \\
\hline 17 & 2.1 & 2.5 & Testis-specific lactate dehydrogenase & Acid base \\
\hline 18 & 1.9 & 2.5 & VEGF* & Angiogenesis \\
\hline 19 & 2.4 & 2.5 & Adenylate kinase 3 & Energy metabolism \\
\hline 20 & 1.7 & 2.4 & Dual specificity phosphatase I (DUSPI/CLI00/MKPI) & Cell signalling \\
\hline 21 & 1.7 & 2.1 & DEC I & Differentiation \\
\hline 22 & 2.6 & 2.1 & Glucose-6-phosphate isomerase & Glucose metabolism \\
\hline 23 & 2.1 & 2.1 & Fructose-bisphosphate aldolase A & Glucose metabolism \\
\hline \multicolumn{5}{|c|}{ Not previously known to be hypoxia regulable } \\
\hline 24 & 2.8 & 8.2 & Solute carrier family 16 member 3 (SLCI6A3) & Acid base \\
\hline 25 & 4.5 & 4.9 & Preferentially expressed antigen of melanoma (PRAME) & Antigen \\
\hline 26 & 2.8 & 4.1 & Importin Beta 3 & Nuclear pore protein \\
\hline 27 & 1.9 & 3.1 & RNAse4* & Antimicrobial? \\
\hline 28 & 2.2 & 2.9 & Protooncogene ABLI & Cell cycle \\
\hline \multicolumn{5}{|l|}{ ESTS } \\
\hline 29 & 3 & 3.9 & 50378_A & EST \\
\hline 30 & 3.2 & 3.3 & 50022_A & EST \\
\hline 31 & 3.5 & 3.3 & 31564_B & EST \\
\hline 32 & 2.1 & 2.4 & $21875 \mathrm{~A}$ & EST \\
\hline
\end{tabular}

Microarray result of eight biological replicates; genes had to be upregulated more than two-fold with high raw signal intensity ( $>$ I 000 units) in more than six of eight replicates to avoid false positives and be included in this list. Eight asterisked genes (*) were also significantly upregulated on the in vivo array. EST = expressed sequence tag.

Table 2 Fold changes of IGFBP-3, RNAse4 and SLCI6A3 by hypoxia (0.1\%) in bladder cancer cell lines, normal cultured human urothelia and HUVE cells analysed by real-time $\mathrm{RT}-\mathrm{PCR}$

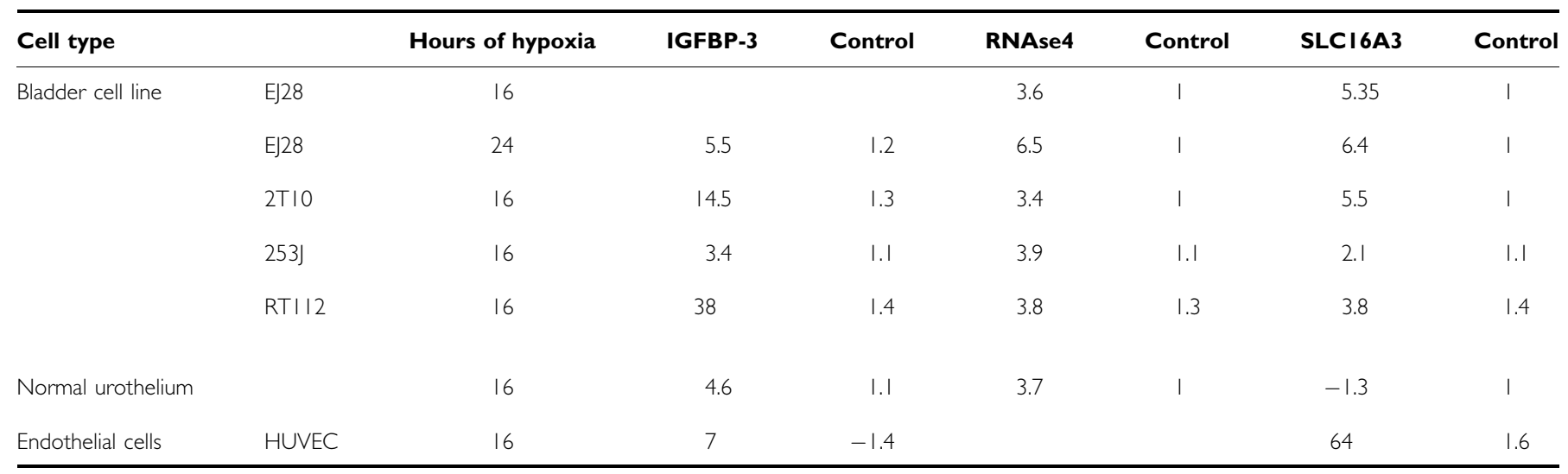

Three replicates of each experiment were performed and if replicates were more than 0.5 cycles different, the result was not accepted. The control gene Beta-2-microglobulin in each experiment did not differ significantly from normoxia to hypoxia but any trend to change of the control gene is demonstrated by minimal fold changes (range - I.4 to I.6). Fold change calculated on the basis of 2 to the power of the change in cycle number at a set threshold. Differences in gene of interest in normoxia and hypoxia all showed a significant difference in average cycle threshold $(P<0.0 \mathrm{I})$ unless indicated. Negative values indicate downregulation. 


\section{Scoring of tumours for necrosis and hypoxia}

To correlate the in vivo transcriptome of these tumours with tumour hypoxia, we scored paraffin sections of the tumours using CA IX stain as a marker of hypoxia. We also scored tumours for

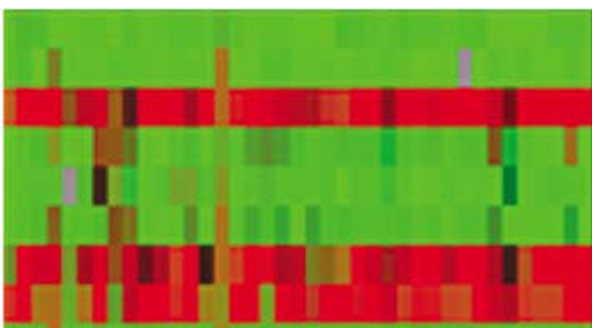

LDH A

EST123474

IGFBP3

LDHC4

DRP-2

LDHC4

IGFBP3

VEGF

GPI

F-B ALDO A

ALDO C

NIP3

PLOD2

HBL

HMOX1

MARCKS

DUSP 1

AK4

NIP3

CCNG2

NDRG1

EST 31564

PLOD2

AK3

GLUT-1

CCNG2

PRAME

CCNG2

PFKFB3

DUSP1

NIP3

HGBE

DEC1

CGI-150

HGBE

EST272176

RNASE4

ADM

P4HA

MXI 1

ABL1

PFKFB3

KPNB3

ABL1

P4HA

SLC16A3

EST50378

MMF

EST50378

PCK2

EGL9 H1

CCNG1 IP

EST21875 the presence of intratumoural necrosis seen with haematoxylin and eosin stain. A total of 32 tumours were available for both scores, 11 invasive and 21 superficial. Necrosis was present in five invasives and two superficials. CA IX scoring was positive in three invasive cancers and 13 superficial tumours. A total of three necrotic tumours were also CA IX positive. GLUT-1 fold changes correlated with CA IX scores $\left(P=0.008 r^{2}=0.21\right.$, Figure 3$)$, and were significantly higher in CA IX-positive tumours (means 0.9 vs 1.8 $P=0.03$ two-tailed $t$-test variances not assumed to be equal).

\section{Urine IGFBP-3 protein is raised in bladder cancer}

Insulin-like growth factor binding protein 3 at the transcript level was upregulated higher and more frequently than VEGF in both in vitro and in vivo arrays. We therefore measured levels of IGFBP-3 protein in the urine (Figure 4). Urine from 157 bladder cancer patients and controls was collected prospectively and IGFBP-3 levels were measured by ELISA. There was a significant increase in urinary IGFBP-3 concentration from control/clear groups to superficial cancers to invasive cancers, $P<0.01$ for superficial $v s$ control/clear, $P<0.01$ for invasive $v s$ control/clear (IGFBP-3 $\mathrm{ng} \mathrm{ml}^{-1}$ mean (standard deviation); controls $15.2 \mathrm{ng} \mathrm{ml}^{-1}$ (7.55); clears $14.6 \mathrm{ng} \mathrm{ml}^{-1}$ (8.1); superficial $27.7 \mathrm{ng} \mathrm{ml}^{-1}$ (29); invasive $\left.55.1 \mathrm{ng} \mathrm{ml}^{-1}(40)\right)$. After correction for urinary creatinine, significance $(P<0.01)$ was retained for invasive tumours, but not for the superficial group. There were 15 stage T1G3 tumours in the superficial group. There was no significant difference between levels in the urine of T1G3 tumours and other superficial tumours or with the invasive group. If a single exceptionally high $(>4$ standard deviations) level in the superficial group is excluded, the mean corrected levels of urine IGFBP-3 increase with stage and grade: superficial (T1G2 or lower) $351 \mathrm{ng} \mathrm{mmol}^{-1} \mathrm{Cr}$ (creatinine); T1G3 $479 \mathrm{ng} \mathrm{mmol}^{-1} \mathrm{Cr}$; invasive $733 \mathrm{ng} \mathrm{mmol}^{-1} \mathrm{Cr}$.

One of the anonymously taken medical student controls had a level of IGFBP-3 five standard deviations higher than the rest of this group. Despite this, the significant difference between this group and the bladder cancer group held. All medical student control urines dipped negative for blood so an undiagnosed cancer is unlikely in such a young person. The likely explanation is an exercise-induced rise in IGFBP-3 (Manetta et al, 2002).

\section{DISCUSSION}

The in vitro analysis of hypoxia-induced genes showed several genes already well recognised to be induced by hypoxia, and also other genes likely to be of functional importance in the response to hypoxia.

SLC16A3 is a new hypoxia-regulated gene. This occurred particularly in HUVEC cells, and also in bladder and breast cell lines, but not in cultured normal urothelium. It is a member of the proton-linked transmembrane monocarboxylate transporter (MCT) family with high affinity for lactate (Halestrap and Price, 1999). It is particularly high in the white skeletal muscle, white blood cells and cell lines, suggesting that it may be of particular

Figure I Graphic representation of array results of in vivo hypoxia gene expression in bladder cancers, for all genes induced by hypoxia in vitro (as listed in Table I): in order of Genespring 'Interest' function that places the most statistically trustworthy and greatest fold changes towards the top of the list. Some genes have more than one result as they were represented by more than one spot on the array. 39 columns $=39$ tumour samples. Samples I (on left) to $26=$ superficial, samples $27-39=$ muscle invasive. One row = one gene as labelled. Tumour cDNA was competitively hybridised against a panel of II cancer cell lines. Red=two-fold or more upregulation, green = downregulation, brown equals no change. Brightness $=$ statistical trust. 


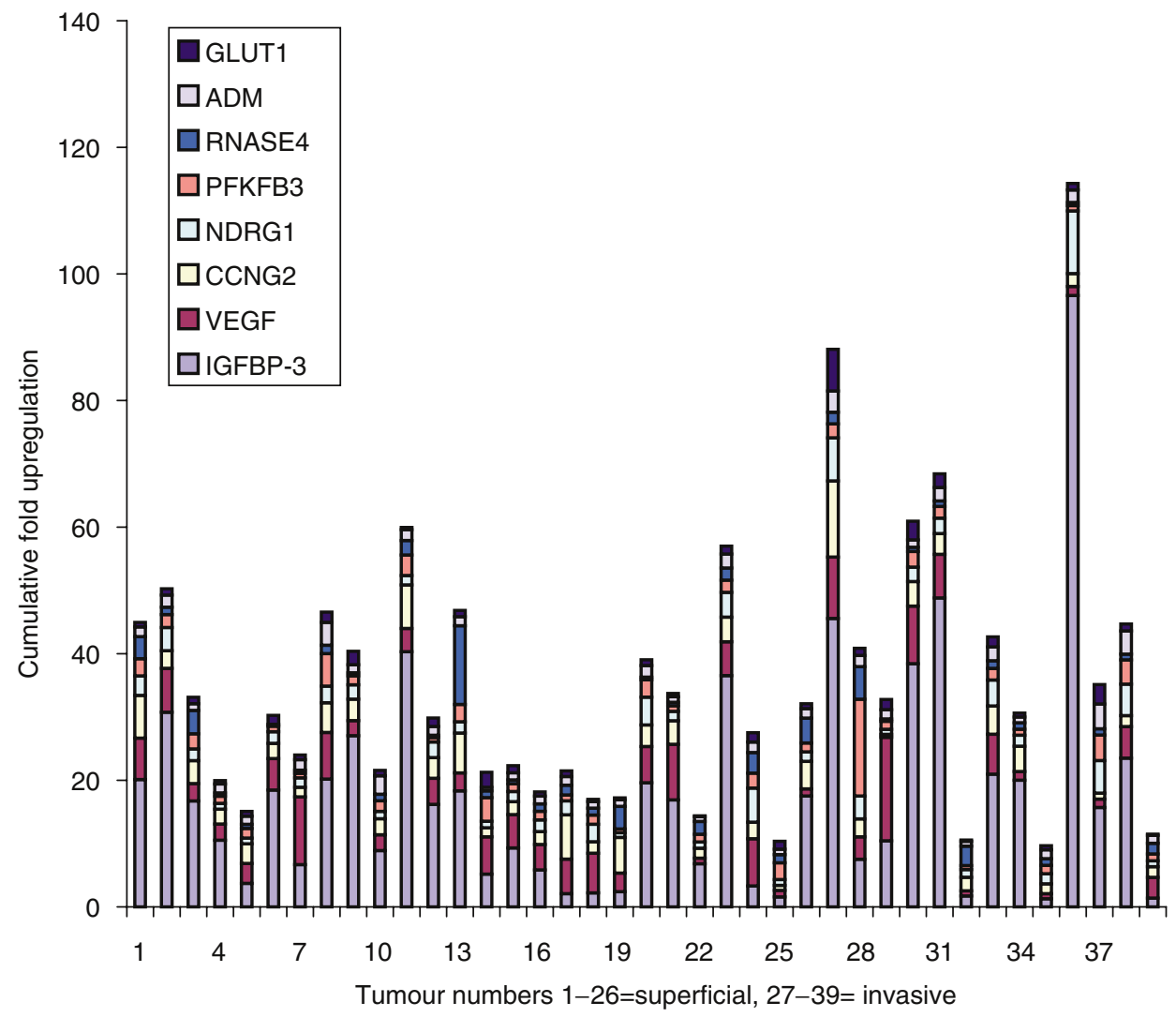

Figure 2 Tumour samples categorised by the fold upregulation of the eight genes upregulated by hypoxia in the cell line and upregulated more than twofold in more than five tumour samples on the in vivo array. Insulin-like growth factor binding protein 3 makes the largest fold contribution and is upregulated more than two-fold in the majority of samples.

importance in tissues that rely on high levels of glycolysis for ATP production.

The upregulation of RNAse4 by hypoxia is also novel. The human enzyme is secreted into plasma and the gene (Rosenberg and Dyer, 1995) shares various identical $5^{\prime}$-untranslated regions on its mRNA with the angiogenic factor angiogenin, suggesting that expression of the proteins is under similar control, with obvious implications for their biological activities. Angiogenin is upregulated by hypoxia in cell lines and is raised in the blood and tumours of patients with bladder cancer (Miyake et al, 1999).

On the tumour array, 70 of $6000(1.2 \%)$ genes were upregulated more than two-fold in over 30 tumours. Three of these 70 genes $(4.3 \%)$ were hypoxia inducible on the in vitro array (IGFBP-3, VEGF, CCNG2). Since only 32 of $6000(0.53 \%)$ genes on the in vitro array were upregulated by hypoxia, hypoxia-induced genes are eight times over-represented in the group of genes most upregulated on the tumour array $\left(P<0.01 \chi^{2}\right.$ test). However, of the 32 genes upregulated in vitro, only eight were upregulated in the tumour samples.

In contrast, 24 were downregulated more than 0.5 -fold in more than five tumour samples (green) in vivo (Figure 1). There are several possible reasons for this. The in vivo array, comparing as it does tumour samples to a panel of cell lines may be highlighting the more complex influences on gene expression present in the three-dimensional environment. Three-dimensional geometry of in vitro cell growth alone has been shown to have dramatic influences on biological function and gene expression profile (Dangles et al, 2002).

The apparent downregulation of NIP3, Aldolase C, PLOD2 and other hypoxia-inducible genes on the in vivo array in all tumour samples, even in tumours where hypoxia and necrosis were present, may represent a relative basal upregulation of these genes in the monolayer cell culture panel. The subset of known hypoxiainducible genes that were clearly upregulated in vitro but not in vivo in general was less inducible. The combination of pure in vitro cancer cell populations with basal upregulation of the pathways, possibly via oncogene pathways know to regulate HIF, is probably sufficient to explain this.

Since we used a widely described cell line panel as a control, this has some implications for interpretation of such arrays. In our study we were specifically investigating a defined pathway, but if we used the tumour array results alone without considering genes in the same pathway, this effect may not have been noted.

We might have expected all eight genes significantly upregulated by hypoxia in vitro and in vivo to correlate with tumour scores of hypoxia and necrosis in vivo. Glucose transporter 1 (GLUT1) transcription fold changes on the in vivo array showed a significant correlation with the immunohistochemical CA IX score as a surrogate marker of hypoxia. Glucose transporter and ADM also showed significant correlation with each other. Glucose transporter 1 protein immunohistochemistry has previously been shown to correlate with CA IX staining in cervical cancer and, like CA IX, it has been shown to be a marker of tumour hypoxia (Airley et al, 2001, 2003). The correlation here shows that the same is also likely to be true for bladder cancer. Adrenomedullin, a secreted protein, may also prove to be useful as a marker of hypoxic tumours in the urine. The other genes did not correlate with tumour hypoxia and necrosis scores and were upregulated in many tumours. The result highlights the complexity and heterogeneity of the hypoxia response, suggesting that the final pattern may be individual. 

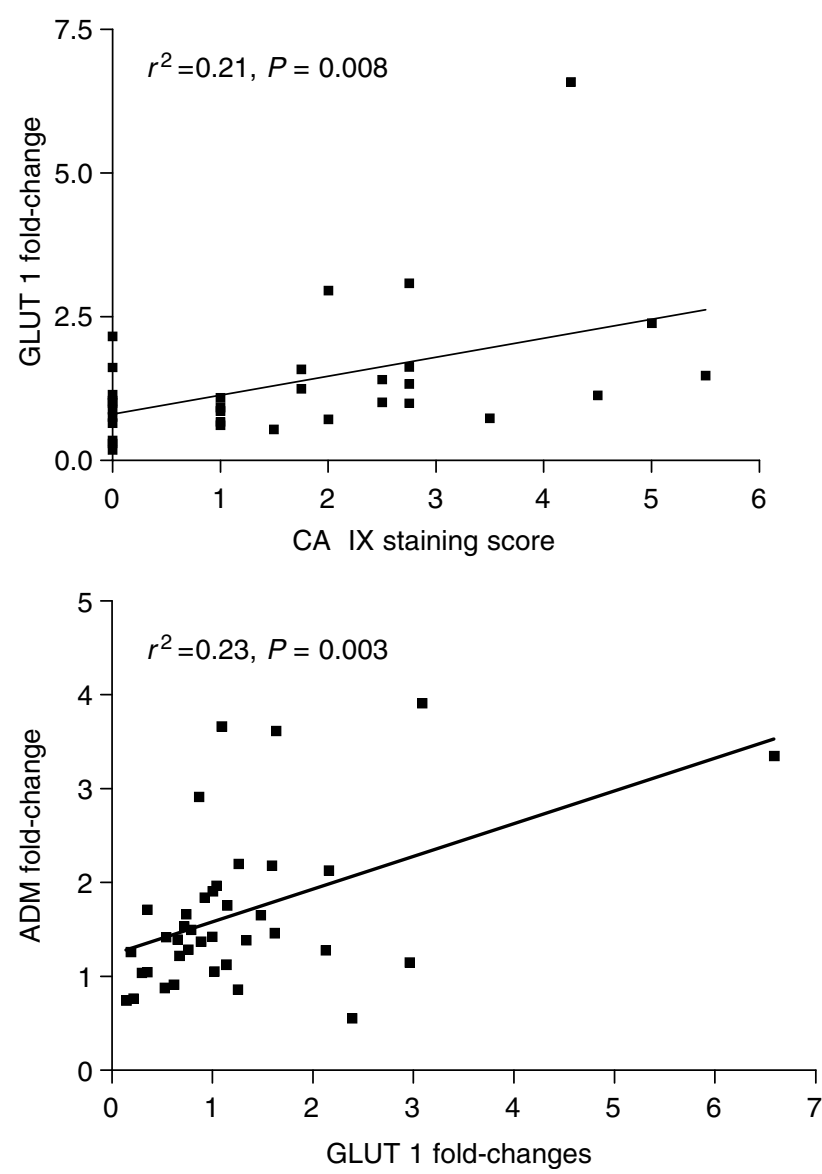

Figure 3 Glucose transporter | fold changes in vivo correlated with scores for CA IX staining of tumours by immunohistochemistry as a surrogate marker of hypoxia. Adrenomedullin fold changes correlated with GLUT-I fold changes. Carbonic anhydrase IX itself was not on the array.

In addition to the hypoxic regulation of gene transcripts, oncogenic changes specific to bladder cancer, but which are not found in the majority of the cell line panel, may also contribute to their expression. Examples of genes that are mutated in bladder cancer include p53, PTEN and H-ras, which upregulate HIF (Krishnamachary et al, 2003). The HER2 oncogene is known to upregulate IGFBP-3, and was upregulated on the in vivo array more than two-fold in 22 of 39 tumour samples.

The gene most frequently and proportionally upregulated was IGFBP-3, which is known to be hypoxia inducible in a number of cell lines. We show that this is also true of bladder cell lines and is not specific to cancer, with upregulation in human cultured urothelium (4.6-fold) and HUVE cells (7-fold). Insulinlike growth factor binding protein 3 may act as a direct apoptotic response to hypoxia, and this implies that there are major selective mechanisms in vivo to overcome this pathway and suggests that antagonising the IGF1 receptor could have high selectivity in cancer, with endogenous IGFBP-3 synergising with such inhibition.

In contrast to its extracellular IGF-binding role, an intracellular role of IGFBP-3 has been described (Schedlich et al, 2003), with phosphorylation increasing nuclear import of IGFBP-3, with release of IGF. The mechanism involves interaction with Importin Beta (Schedlich et al, 2003), a gene not previously recognised to be regulated by hypoxia, which was induced by hypoxia in our study (4.1-fold) in vitro. Thus, induction of IGFBP3 may have a more complex role then previously reported.
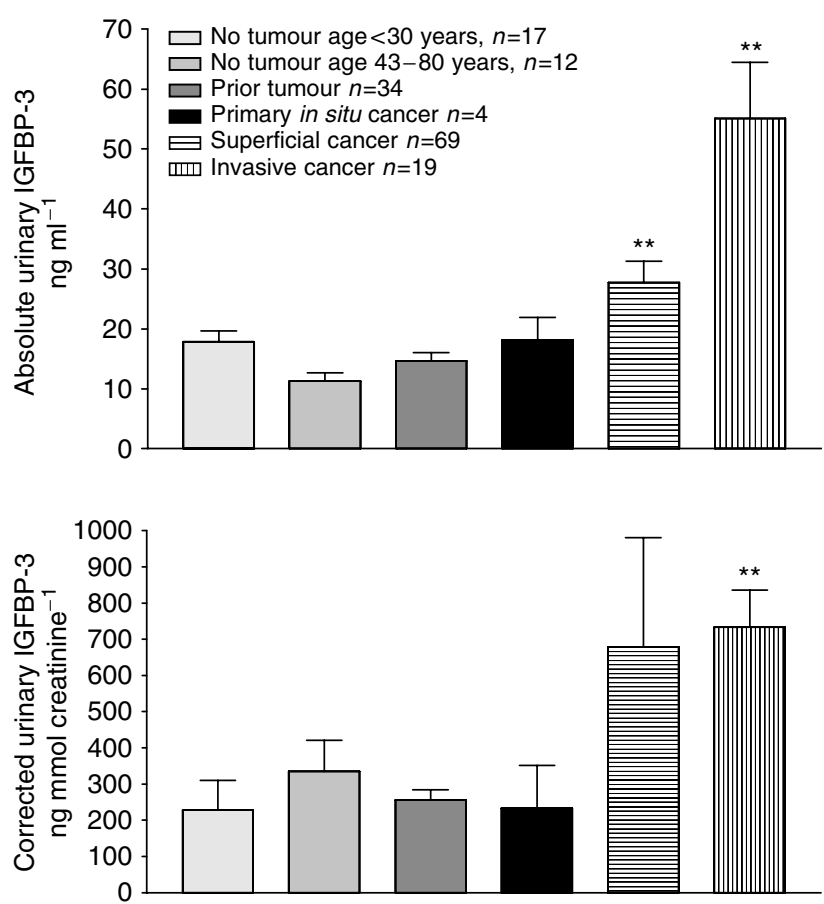

Figure 4 Levels of IGFBP-3 in urine: TOP absolute level, BOTTOM corrected level for urine creatinine. Invasive significantly higher than all control groups in both cases. Superficial significantly higher than control groups for absolute levels only $(* *=P<0.0 \mathrm{I})$. Error bar = standard error.

The finding of raised IGFBP-3 in the urine of bladder cancer patients has not been previously noted. In vitro experiments on cell growth and IGFBP-3 make it likely that the levels of IGFBP-3 seen here in urine are of clinical significance. Levels as low as $10 \mathrm{ng} \mathrm{ml}^{-1}$ and more commonly $30-50 \mathrm{ng} \mathrm{ml}^{-1}$ have been shown to have inhibitory effects on growth of neoplastic cells in vitro (Martin and Baxter, 1999; Ewton et al, 2002). It is often assumed to be growth inhibitory, but IGFBP-3 has a stimulatory effect on the growth of smooth muscle bladder cells in vitro (Weinzimer et al, 2001). It must also be noted that the ELISA measures both proteolysed fragments and intact IGFBP-3 (Diamandi et al, 2000). The rise we measured may reflect increased proteolysis of IGFBP-3 that would make more IGF available to the tumour. However, the array data suggest at least that direct upregulation of mRNA levels of IGFBP-3 occur, with or without increased proteolysis.

Cyclin G2 is known to be regulated by the VHL/hypoxia pathway (Wykoff et al, 2000). It is a negative regulator of the cell cycle with peak expression in $\mathrm{S}$ phase and it stimulates apoptosis (Bennin et al, 2002). Cyclin G2 RNA levels were shown in another array to be expressed at a lower level in stage T2 bladder tumours than in Ta (Dyrskjot et al, 2003). Cyclin G2 was also upregulated in Ta tumours compared to normal tissue. This contrasts with the result on the tumour array here, where there was no significant difference in Cyclin G2 fold change from Ta to T2 tumours. This difference may be because our array used a panel of cell lines as reference rather than normal bladder tissue.

Overall, these results show that there is concordance in vivo for a subset of hypoxia-induced genes (ADM, GLUT1 and CA IX protein), which may provide a hypoxia signature for analysis of gene array data. Hoskin et al (2003) showed that GLUT1 and CAIX expressions in invasive bladder cancer were correlated with hypoxia and outcome of radiation therapy. However, there is also an individual pattern of expression for each patient. 
Hypoxia-regulated genes are disproportionately upregulated in primary bladder cancer. The induction of putative proapoptotic, cell cycle arrest pathways commonly occurs (IGFBP-3 and CCNG2) and may act to select apoptosis resistance pathways in vivo, and therefore a more comprehensive analysis in clinical trials may help refine predictions of those who would benefit from modulation of hypoxia and the variability in outcome even when using GLUT1.

\section{REFERENCES}

Airley R, Loncaster J, Davidson S, Bromley M, Roberts S, Patterson A, Hunter R, Stratford I, West C (2001) Glucose transporter glut-1 expression correlates with tumor hypoxia and predicts metastasis-free survival in advanced carcinoma of the cervix. Clin Cancer Res 7: 928-934

Airley RE, Loncaster J, Raleigh JA, Harris AL, Davidson SE, Hunter RD, West CM, Stratford IJ (2003) GLUT-1 and CAIX as intrinsic markers of hypoxia in carcinoma of the cervix: relationship to pimonidazole binding. Int $J$ Cancer 104: 85-91

Bennin DA, Don AS, Brake T, McKenzie JL, Rosenbaum H, Ortiz L, DePaoli-Roach AA, Horne MC (2002) Cyclin G2 associates with protein phosphatase $2 \mathrm{~A}$ catalytic and regulatory B' subunits in active complexes and induces nuclear aberrations and a G1/S phase cell cycle arrest. J Biol Chem 277: 27449-27467

Bochner BH, Cote RJ, Weidner N, Groshen S, Chen SC, Skinner DG, Nichols PW (1995) Angiogenesis in bladder cancer: relationship between microvessel density and tumor prognosis. J Natl Cancer Inst 87: $1603-1612$

Brizel DM, Scully SP, Harrelson JM, Layfield LJ, Bean JM, Prosnitz LR, Dewhirst MW (1996) Tumor oxygenation predicts for the likelihood of distant metastases in human soft tissue sarcoma. Cancer Res 56: 941 - 943

Camp RL, Charette LA, Rimm DL (2000) Validation of tissue microarray technology in breast carcinoma. Lab Invest 80: 1943-1949

Chow NH, Liu HS, Chan SH, Cheng HL, Tzai TS (1999) Expression of vascular endothelial growth factor in primary superficial bladder cancer. Anticancer Res 19: 4593-4597

Cordon-Cardo C, Bander NH, Fradet Y, Finstad CL, Whitmore WF, Lloyd KO, Oettgen HF, Melamed MR, Old LJ (1984) Immunoanatomic dissection of the human urinary tract by monoclonal antibodies. J Histochem Cytochem 32: 1035-1040

Crew J, Fuggle S, Bicknell R, Cranston D, Benedetti AD, Harris A (2000) Eukaryotic initiation factor- $4 \mathrm{E}$ in superficial and muscle invasive bladder cancer and its correlation with vascular endothelial growth factor expression and tumor progression. Br J Cancer 82: 161-166

Crew JP, O’Brien T, Bicknell R, Fuggle S, Cranston D, Harris AL (1999) Urinary vascular endothelial growth factor and its correlation with bladder cancer recurrence rates. J Urol 161: 799-804

Dangles V, Lazar V, Validire P, Richon S, Wertheimer M, Laville V, Janneau JL, Barrois M, Bovin C, Poynard T, Vallancien G, Bellet D (2002) Gene expression profiles of bladder cancers: evidence for a striking effect of in vitro cell models on gene patterns. Br J Cancer 86: 1283-1289

Diamandi A, Mistry J, Krishna RG, Khosravi J (2000) Immunoassay of insulin-like growth factor-binding protein-3 (IGFBP-3): new means to quantifying IGFBP-3 proteolysis. J Clin Endocrinol Metab 85: 2327-2333

Dubeau L, Jones PA (1987) Growth of normal and neoplastic urothelium and response to epidermal growth factor in a defined serum-free medium. Cancer Res 47: 2107-2112

Dyrskjot L, Thykjaer T, Kruhoffer M, Jensen JL, Marcussen N, HamiltonDutoit S, Wolf H, Orntoft TF (2003) Identifying distinct classes of bladder carcinoma using microarrays. Nat Genet 33: $90-96$

Ewton DZ, Kansra S, Lim S, Friedman E (2002) Insulin-like growth factor-I has a biphasic effect on colon carcinoma cells through transient inactivation of forkhead1, initially mitogenic, then mediating growth arrest and differentiation. Int J Cancer 98: 665-673

Halestrap AP, Price NT (1999) The proton-linked monocarboxylate transporter (MCT) family: structure, function and regulation. Biochem J 343(Part 2): $281-299$

Harris AL (2002) Hypoxia - a key regulatory factor in tumour growth. Nat Rev Cancer 2: $38-47$

Hockel M, Schlenger K, Aral B, Mitze M, Schaffer U, Vaupel P (1996) Association between tumor hypoxia and malignant progression in advanced cancer of the uterine cervix. Cancer Res 56: 4509-4515

\section{ACKNOWLEDGEMENTS}

We thank the Royal College of Surgeons for funding the first year of this project and Oxford Health Services Research Committee for further funding in the second year, and Margaret Knowles in Leeds for the normal urothelial cell culture protocol. This research was supported by Cancer Research UK, Royal College of Surgeons of England and Oxford Regional Health Services Research Committee.

Hoskin PJ, Sibtain A, Daley FM, Wilson GD (2003) GLUT1 and CAIX as intrinsic markers of hypoxia in bladder cancer: relationship with vascularity and proliferation as predictors of outcome of ARCON. $\mathrm{Br} J$ Cancer 89: $1290-1297$

Krishnamachary B, Berg-Dixon S, Kelly B, Agani F, Feldser D, Ferreira G, Iyer N, LaRusch J, Pak B, Taghavi P, Semenza GL (2003) Regulation of colon carcinoma cell invasion by hypoxia-inducible factor 1 . Cancer Res 63: $1138-1143$

Manetta J, Brun JF, Maimoun L, Callis A, Prefaut C, Mercier J (2002) Effect of training on the GH/IGF-I axis during exercise in middle-aged men: relationship to glucose homeostasis. Am J Physiol Endocrinol Metab 283: E929-E936

Martin JL, Baxter RC (1999) Oncogenic ras causes resistance to the growth inhibitor insulin-like growth factor binding protein-3 (IGFBP-3) in breast cancer cells. J Biol Chem 274: 16407-16411

Miyake H, Hara I, Yamanaka K, Gohji K, Arakawa S, Kamidono S (1999) Increased angiogenin expression in the tumor tissue and serum of urothelial carcinoma patients is related to disease progression and recurrence. Cancer 86: $316-324$

Nikitenko LL, Smith DM, Hague S, Wilson CR, Bicknell R, Rees MC (2002) Adrenomedullin and the microvasculature. Trends Pharmacol Sci 23: $101-103$

Nocito A, Bubendorf L, Maria Tinner E, Suess K, Wagner U, Forster T, Kononen J, Fijan A, Bruderer J, Schmid U, Ackermann D, Maurer R, Alund G, Knonagel H, Rist M, Anabitarte M, Hering F, Hardmeier T, Schoenenberger AJ, Flury R, Jager P, Luc Fehr J, Schraml P, Moch H, Mihatsch MJ, Gasser T, Sauter G (2001) Microarrays of bladder cancer tissue are highly representative of proliferation index and histological grade. J Pathol 194: $349-357$

Nordsmark M, Overgaard J (2000) A confirmatory prognostic study on oxygenation status and loco-regional control in advanced head and neck squamous cell carcinoma treated by radiation therapy. Radiother Oncol 57: $39-43$

Perou CM, Sorlie T, Eisen MB, van de Rijn M, Jeffrey SS, Rees CA, Pollack JR, Ross DT, Johnsen H, Akslen LA, Fluge O, Pergamenschikov A, Williams C, Zhu SX, Lonning PE, Borresen-Dale AL, Brown PO, Botstein D (2000) Molecular portraits of human breast tumours. Nature 406: $747-752$

Rosenberg HF, Dyer KD (1995) Human ribonuclease 4 (RNase 4): coding sequence, chromosomal localization and identification of two distinct transcripts in human somatic tissues. Nucleic Acids Res 23: $4290-4295$

Sanchez-Carbayo M, Socci ND, Lozano JJ, Li W, Charytonowicz E, Belbin TJ, Prystowsky MB, Ortiz AR, Childs G, Cordon-Cardo C (2003) Gene discovery in bladder cancer progression using cDNA microarrays. Am J Pathol 163: 505-516

Schaafsma HE, Ramaekers FC, van Muijen GN, Ooms EC, Ruiter DJ (1989) Distribution of cytokeratin polypeptides in epithelia of the adult human urinary tract. Histochemistry 91: $151-159$

Schedlich LJ, Nilsen T, John AP, Jans DA, Baxter RC (2003) Phosphorylation of insulin-like growth factor binding protein-3 by deoxyribonucleic acid-dependent protein kinase reduces ligand binding and enhances nuclear accumulation. Endocrinology 144: $1984-1993$

Theodoropoulos VE, Lazaris A, Sofras F, Gerzelis I, Tsoukala V, Ghikonti I, Manikas K, Kastriotis I (2004) Hypoxia-inducible factor 1 alpha expression correlates with angiogenesis and unfavorable prognosis in bladder cancer. Eur Urol 46: 200-208

Turner KJ, Crew JP, Wykoff CC, Watson PH, Poulsom R, Pastorek J, Ratcliffe PJ, Cranston D, Harris AL (2002) The hypoxia-inducible genes 
VEGF and CA9 are differentially regulated in superficial $v s$ invasive bladder cancer. Br J Cancer 86: 1276-1282

Weinzimer SA, Gibson TB, Collett-Solberg PF, Khare A, Liu B, Cohen P

(2001) Transferrin is an insulin-like growth factor-binding protein-3 binding protein. J Clin Endocrinol Metab 86: 1806-1813

Wykoff CC, Beasley NJ, Watson PH, Turner KJ, Pastorek J, Sibtain A, Wilson GD, Turley $\mathrm{H}$, Talks KL, Maxwell PH, Pugh CW, Ratcliffe PJ, Harris AL (2000) Hypoxia-inducible expression of tumor-associated carbonic anhydrases. Cancer Res 60: $7075-7083$ 